\title{
Study of $\mathrm{SO}_{2}$ Adsorption on Porous $\mathrm{SiO}_{2}$ Particles Using a Micro-Reactor System
}

\author{
Yumei Wu, Xiaoling Zha, Jin $\mathrm{Xu}^{*}$ \\ Chemical Engineering Department, Wenzhou University, Wenzhou, China \\ Email address: \\ 781129889@qq.com (Yumei Wu),1258406148@qq.com (Xiaoling Zha), xujin@wzu.edu.cn (Jin Xu) \\ ${ }^{*}$ Corresponding author
}

To cite this article:

Yumei Wu, Xiaoling Zha, Jin Xu. Study of $\mathrm{SO}_{2}$ Adsorption on Porous $\mathrm{SiO}_{2}$ Particles Using a Micro-Reactor System. Modern Chemistry. Vol. 5, No. 3, 2017, pp. 43-49. doi: 10.11648/j.mc.20170503.12

Received: March 28, 2017; Accepted: May 11, 2017; Published: May 16, 2017

\begin{abstract}
Immobilized ionic liquids (ILs) with high selective adsorption capacity of $\mathrm{SO}_{2}$ from $\mathrm{N}_{2}$, on porous solid particles such as $\mathrm{SiO}_{2}$, has potential applications on $\mathrm{SO}_{2}$ emission control. As the first step towards the establishment of a comprehensive model for $\mathrm{SO}_{2}$ adsorption on supported IL, the performance of neat $\mathrm{SiO}_{2}$, the support material, was evaluated in this work. A series of adsorption/desorption breakthrough experiments were carried out using a micro-reactor system to investigate the effects of concentration, particle structure and temperature. Theoretical analyses of experimental observations were used to identify the adsorption mechanisms and relative importance of mass transfer processes.
\end{abstract}

Keywords: $\mathrm{SiO}_{2}, \mathrm{SO}_{2}$ Capture, Mass Transfer Kinetics, Micro-Reactor

\section{Introduction}

$\mathrm{SO}_{2}$ emission from fossil fuel combustion is one of the major concerns of air pollution control and has been achieved by various flue gas desulfurization (FGD) techniques $[1,2]$. However, conventional wet FGD method requires large amount of water and results in heavy duty after-treatments while dry FDG method converts $\mathrm{SO}_{2}$ into low-value calcium sulfate. It is therefore desired to develop newel techniques with improved $\mathrm{SO}_{2}$ capture efficiency.

In the last decade, ionic liquids (ILs) have drawn great interests in both academic and industrial communities due to their potential applications on effective absorption of various gaseous species, more specifically, hydrocarbons [3, 4], $\mathrm{CO}_{2}$ [5-8], and $\mathrm{SO}_{2}$ [9]. Han and coworkers successfully synthesized an IL, 1,1,3,3-tetramethylguanidinium (TMGL), and showed that it has high absorption capacity and selectivity of $\mathrm{SO}_{2}$ from $\mathrm{N}_{2}$ [9]. Since then, numerous studies have been carried out to develop new IL materials as well as to investigate the $\mathrm{SO}_{2}$ absorption mechanisms [10-26].

While ILs have the desired properties in terms of selective absorption capacity, decent thermal stability and low vapor pressure, their direct application on industrial scale $\mathrm{SO}_{2}$ removal is restricted by the high viscosities that may result in slow mass transfer rate and small gas-liquid interface area. In addition, the conveying of viscose IL for cyclic operation between absorption and regeneration may present another practical problem. In order to solve these problems, Li and Zhu and their coworkers proposed immobilization of ILs on solid materials by co-polymerization [27] and impregnation-vaporization methods [28]. They found that simply impregnating TMGL on porous silica particles gives a material maintaining the porous structure, large surface area and good mechanical properties of silica while taking the advantages of high $\mathrm{SO}_{2}$ capacity of IL [28]. Thereafter, various supported IL materials have been developed [29].

Theoretical studies have been carried out to investigate the absorption of $\mathrm{SO}_{2}$ in ILs [16, 18, 30]. It has been generally agreed that both chemical and physical absorption are involved. Recently, Li et al. studied $\mathrm{SO}_{2}$ absorption behaviors on a mesoporous molecular sieve supported IL [29]. They divided the overall absorption into two independent and parallel processes, chemical and physical absorptions. Rate constants averaged over a tube reactor and activation energies of both processes were also estimated.

However, the realistic material balance of $\mathrm{SO}_{2}$ in a packed bed is complicated and involves several sub-processes including convection, mass transfer, absorption and desorption. Each sub-process has its characteristic time and 
may play different roles under different conditions. The on-going project in this group is aimed to develop a comprehensive model that could be used to assist design and optimization of practical $\mathrm{SO}_{2}$ capture process using $\mathrm{TMGL} / \mathrm{SiO}_{2}$. For this purpose, $\mathrm{SO}_{2}$ adsorption on neat $\mathrm{SiO}_{2}$ was first investigated in the current work. A series of breakthrough experiments were carried out under various conditions in terms of concentration, particle structure, and temperature. Theoretical analyses were used to identify the adsorption mechanisms and relative importance of various sub-processes under different conditions.

\section{Experiments}

Materials. $\mathrm{SO}_{2}\left(2.6 \%\right.$ in $\left.\mathrm{N}_{2}\right)$ was acquired from Changzhou Jinghua Industrial Gases Co., Ltd., China. $\mathrm{N}_{2}$ (99.99\%) was provided by Wenzhou Longwan Prosperous Gas Co., Ltd., China. $\mathrm{SiO}_{2}$ particle samples with different size and internal structure were purchased from Aladdin Chemistry Co., Ltd., China.

Instruments. The breakthrough experiments were carried out on a modular microreaction system (Bayer, Ehrfeld Mikrotechnik BTS GmbH, German). Figure 1 shows the schematic diagram of experimental setup. The microreaction system has a platform on which various units can be conveniently integrated. A heat exchanger and a micro-reactor (i.d. $0.75 \mathrm{~cm}, 2 \mathrm{ml}$ ) were involved in this study. Both units were connected to a constant temperature circulator (F34-ED Series, Julabo, German) that provided precise temperature control with an accuracy of $\pm 0.1 \mathrm{~K}$. Three mass flow controllers (MFC, Brooks) were used to provide desired feed composition and flowrate. In order to reduce the pressure drop effects on gas density, during the experiments, the column pressure was controlled at 2.0 bar (gauge) by a back pressure valve (BPV in Figure 1, Swagelok Company, America). Temperature and pressure were monitored by corresponding modules located between the heat exchange and the reactor. Outlet $\mathrm{SO}_{2}$ concentration was measured using an FT-IR Spectrometer (Alpha series, Bruker Optik Asia Pacific Limited). The MFCs and the FT-IR Spectrometer were independently collaborated before experiments. A PC system (Dell) was used for data acquisition. An ASAP 2020 accelerated surface area and porosimetry analyzer (Micromeritics, America) was used to characterize various porous $\mathrm{SiO}_{2}$ particle samples.

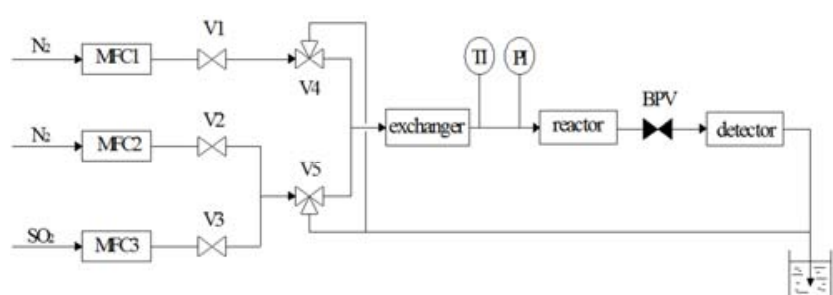

Figure 1. Schematic diagram of the experimental setup.

Procedures. $\mathrm{SiO}_{2}$ particles were pre-treated in an oven at $200^{\circ} \mathrm{C}$ and vacuum for at least 4 hours to remove moisture and then immediately loaded into the reactor tank with the assistance of a vacuum pump. The adsorption/desorption experiments were carried out following the procedure described in Table 1. In step 1, temperature of the heat exchanger and reactor is equilibrated with the circulator for at least $30 \mathrm{~min}$ and, at the mean time, the whole system is purged with $\mathrm{N}_{2}$. Step 2 is to stabilize the flowrates from MFCs 2 and 3 which give the desired feed mixture. Step 3 is for the adsorption experiments. After the system is saturated with feed mixture, V1 is open to stabilized MFC 1 in step 4. The operation is switched to desorption mode in step 5. Step 6 is for the desorption experiment in which the system is purged with $\mathrm{N}_{2}$ provided by MFC 1 .

Table 1. Valve operations during the adsorption/desorption experiment.

\begin{tabular}{llllll}
\hline Step & $\mathbf{V 1}^{\mathbf{a}}$ & $\mathbf{V 2}$ & $\mathbf{V 3}$ & $\mathbf{V 4} \mathbf{4}^{\mathbf{b}}$ & $\mathbf{V 5}$ \\
\hline 1 & $\sqrt{ }$ & $\times$ & $\times$ & 1 & 0 \\
2 & $\sqrt{ }$ & $\sqrt{ }$ & $\sqrt{ }$ & 1 & -1 \\
3 & $\times$ & $\sqrt{ }$ & $\sqrt{ }$ & 0 & 1 \\
4 & $\sqrt{ }$ & $\sqrt{ }$ & $\sqrt{ }$ & -1 & 1 \\
5 & $\sqrt{ }$ & $\sqrt{ }$ & $\sqrt{ }$ & 1 & -1 \\
6 & $\sqrt{ }$ & $\times$ & $\times$ & 1 & 0 \\
\hline
\end{tabular}

a: V1,V2, and V3 are ball valves. $\sqrt{ }$ open; $\times$ close.

b: V4 and V5 are triple valves. 1 to reactor; 0 close; -1 to alkaline solution.

\section{Theories}

Throughout this study, the experiments were carried out under fixed temperatures. In addition, $\mathrm{SO}_{2}$ feed concentration involved in this study was lower than $0.5 \%$. The adsorption heat effects can therefore be neglected. It was also observed that the column pressure drop during experiments was less than 0.12 bar, which is negligible compared with the absolute pressure of 3.0 bar in the reactor. Therefore, it is reasonable to assume that the experiments were carried out under isothermal and isobaric conditions. As such, material balance of the adsorbate, $\mathrm{SO}_{2}$, can be described by:

$$
\begin{gathered}
\frac{\partial c}{\partial t}+\phi \frac{\partial q}{\partial t}+u \frac{\partial c}{\partial z}-D_{L} \frac{\partial^{2} c}{\partial z^{2}}=0 \\
\frac{\partial q}{\partial t}=f(q, c)
\end{gathered}
$$

where $\mathrm{c}$ and $\mathrm{q}$ are concentrations in the mobile and stationary phases, $\mathrm{t}$ is time, $\mathrm{z}$ is axial coordinate, $\varphi$ is phase ratio related to column voidage $\varepsilon$ by $\phi=\frac{(1-\varepsilon)}{\varepsilon}, \mathrm{u}$ is the interstitial velocity of mobile phase, $D_{L}$ is coefficient of axial dispersion mainly contributed to molecular diffusion and eddy diffusion, $f$ defines the accumulation rate in particles as a function of concentrations. In general, the accumulation rate is affected by mass transfer, adsorption and desorption rates (or equilibrium). If the equilibrium can be fast established, eqn (2) reduces to

$$
\frac{\partial q}{\partial t}=k_{m}\left(q-q^{*}(c)\right)
$$

where $\mathrm{km}$ is the overall mass transfer coefficient and $\mathrm{q}^{*}$ is the 
solid phase concentration in equilibrium with the bulk. If the mass transfer is also fast, eqn (2) becomes

$$
q \equiv q^{*}(c)
$$

Eqn (1) coupled with eqn (3) and (4) are normally referred to as transport-dispersion (TD) and equilibrium-dispersion (ED) models.

\section{Results and Discussion}

In this work, a series of breakthrough experiments were carried out to investigate effects of feed concentration, temperature, particle structure on the behaviors of $\mathrm{SO}_{2}$ adsorption and desorption on porous $\mathrm{SiO}_{2}$ particles. The results are presented and discussed in this section.

\section{Effects offeed concentration.}

Figure 2 shows $\mathrm{SO}_{2}$ adsorption/desorption curves on a porous $\mathrm{SiO}_{2}$ sample (particle size $150-280 \mu \mathrm{m}$ ) measured $45^{\circ} \mathrm{C}$. Noted is that, for easy comparison, the concentration was converted to dimensionless form. It is seen that, during adsorption, the breakthrough time decreases with increased concentration but the divergence begins to diminish at concentration higher than $0.4 \%$. On the other hand, during desorption period, the breakthrough starts at about $2.5 \mathrm{~min}$, almost independent of concentration. The measured desorption breakthrough curves of concentrations $0.3 \%, 0.4 \%$ and $0.5 \%$ essentially overlap each other while those of lower concentrations exhibit delayed tails.

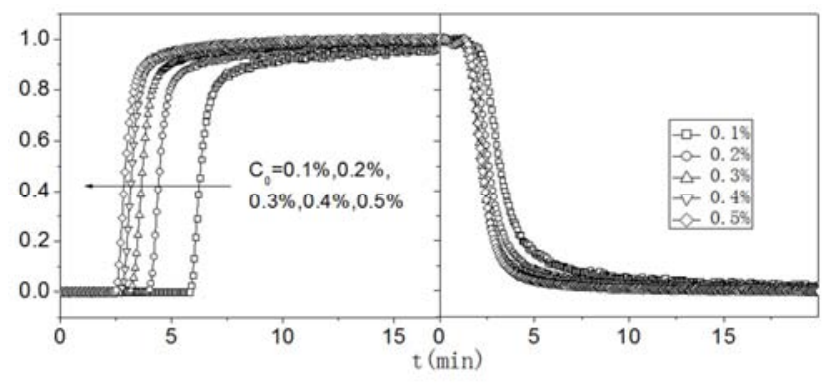

Figure 2. Dimensionless adsorption/desorption curves of $\mathrm{SO}_{2}$ on a porous $\mathrm{SiO}_{2}$ sample. Concentration $0.1 \%$ to $0.5 \%$; temperature $45^{\circ} \mathrm{C}$; particle size $150-280 \mu \mathrm{m}$.

Consider the TD reactor model (eqns 1 and 3) described in Section 3. If the adsorption follows Henry's Law, i.e., $\mathrm{q}^{*}=\mathrm{Hc}$, it may be proven that TD model can be simplified to ED model with DL replaced by Deff [31],

$$
(1+\phi H) \frac{\partial c}{\partial t}+u \frac{\partial c}{\partial z}-D_{e f f} \frac{\partial^{2} c}{\partial z^{2}}=0
$$

where effective diffusivity, Deff, accounts for both axial dispersion and finite mass transfer effects:

$$
D_{e f f}=D_{L}+\frac{u^{2}}{H k_{m} \phi}\left(\frac{\phi H}{1+\phi H}\right)^{2}
$$

In addition, $k_{m}$ is independent of concentration in the linear range. As a result, in the case of linear adsorption, the breakthrough behaviors should be invariant with feed concentration, which is contradicting with the above observations. It may therefore be concluded that adsorption of $\mathrm{SO}_{2}$ on porous $\mathrm{SiO}_{2}$ is a non-linear process. The non-linear feature is more significant in the low concentration range and during the adsorption period.

Another important observation from Figure 2 is that, at the constant temperature of $45^{\circ} \mathrm{C}$, adsorbed $\mathrm{SO}_{2}$ cannot be completely generated by the purge of $\mathrm{N}_{2}$. Mole numbers of $\mathrm{SO}_{2}$ accumulated during adsorption and purged out during desorption can be calculated by

$$
\begin{gathered}
A d s=Q \int_{0}^{\infty}\left(c_{0}-c\right) d t \\
\text { Des }=Q \int_{0}^{\infty} c d t
\end{gathered}
$$

where $\mathrm{Q}$ is the flowrate, $c_{0}$ is the feed concentration, and $c$ is the outlet concentration recorded by the FT-IR Spectrometer. $A d s$ and Des are plotted against feed concentration in Figure 3. The figure shows that i) both $A d s$ and Des increase with feed concentration and the plots form two straight lines; ii) the two straight lines are parallel, i.e., the balance between $A d s$ and Des is barely dependent on concentration.

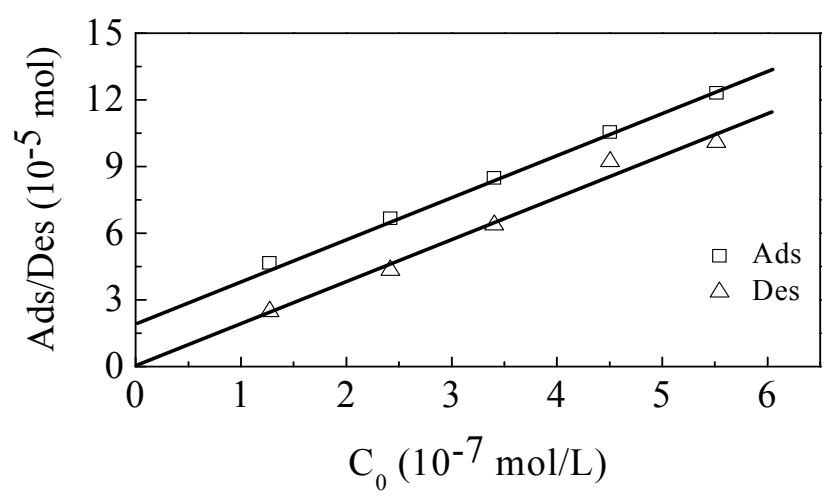

Figure 3. Ads and Des against feed concentration and the fits by eqn (9).

Based on these observations, the overall $\mathrm{SO}_{2}$ accumulation in the system during adsorption can be divided into two fractions:

$$
A d s=D e s+b=a c+b
$$

where $a$ is the equal slope shared by the two lines, $b$ is the intercept of desorption line. The first term proportional to concentration accounts for $\mathrm{SO}_{2}$ accumulation in the gas phase and linear adsorption in the solid phase, i.e.,

$$
a=V_{D}+V_{\text {reactor }}\left(\varepsilon+(1-\varepsilon) H_{V}\right)
$$

where $V_{D}$ is the extra column volume, $V_{\text {reactor }}$ is the reactor volume, $H_{V}$ is dimensionless Henry's constant of linear physical adsorption based on particle volume. The second 
term, $b$, refers to adsorption on the sites functioning as a sink with a concentration independent $\mathrm{SO}_{2}$ capacity. The accumulation of $\mathrm{SO}_{2}$ in this sink is stable and cannot be desorbed at $45^{\circ} \mathrm{C}$. Simultaneously fitting the $A d s$ and Des data using two straight lines with a shared slope and 0 intercept of the Des line gives estimates to parameters in eqn (10). The fits are shown in Figure 3. The acquired values of $a$ and $b$ are $1.91 \times 10^{-4} \mathrm{~m}^{3}$ and $1.92 \times 10^{-5} \mathrm{~mol}$, respectively.

\section{Effects of particle structure}

In order to further investigate the effects of particle structure on $\mathrm{SO}_{2}$ adsorption on porous $\mathrm{SiO}_{2}$, the similar experiments were carried out using three porous $\mathrm{SiO}_{2}$ samples. The loadings and characteristics of these samples are summarized in Table 2 together with the acquired $a$ and $b$ values. The detailed data and fitting results are omitted in this article for conciseness and will be reported elsewhere [32].

Table 2. Particle structures and the acquired $a, b, N E T P$ for different samples at $45^{\circ} \mathrm{C}$.

\begin{tabular}{|c|c|c|c|c|c|c|c|c|}
\hline No & Patic-le size $(\mu \mathrm{m})$ & $\begin{array}{l}\text { Load-ing } \\
(\mathrm{mg})\end{array}$ & $\begin{array}{l}\text { Surf-ace area } \\
\left(\mathrm{m}^{2} / \mathrm{g}\right)\end{array}$ & $\begin{array}{l}\text { Pore volu-me } \\
\left(\mathrm{m}^{3} / \mathrm{g}\right)\end{array}$ & $\begin{array}{l}\text { Pore } \\
\text { diame-ter(nm) }\end{array}$ & a $\left(10^{-4} \mathrm{~m}^{3}\right)$ & b $\left(10^{-5} \mathrm{~mol}\right)$ & NETP \\
\hline I & $37-54$ & 0.828 & 386 & 0.98 & 7.0 & 1.94 & 1.8 & 13 \\
\hline II & $88-150$ & 0.818 & 183 & 1.07 & 14.9 & 0.96 & 2.2 & 12 \\
\hline
\end{tabular}

It may be seen from Table 2 that mass loadings of the three samples were in the range of $0.836 \pm 0.02 \mathrm{~g}$. Samples I and III have similar internal structure while sample II has a smaller surface area and a larger average micro-pore size. The independently acquired $a$ values increases following the sequence of II, I and III. Plotting $a$ against total surface area form a straight line as shown in Figure 4. Since extra column and reactor voidage volumes are in the order of few milliliters, their contributions to $a$ can be neglected. Therefore, the trend in Figure 4 suggests that $H_{V}$ is proximately proportional to total surface area.

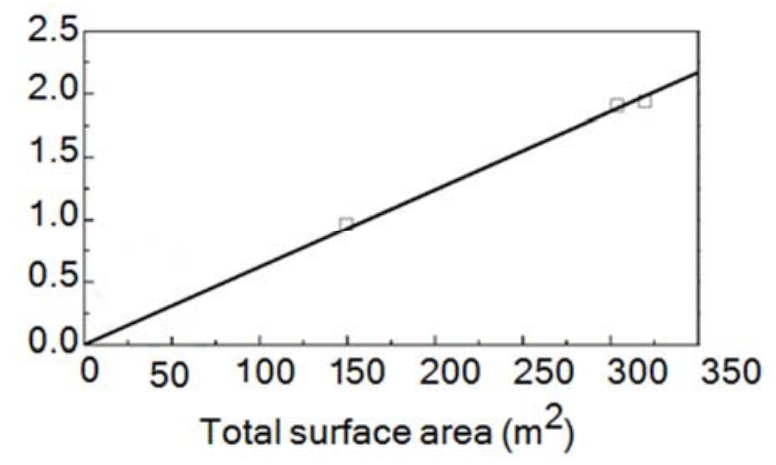

Figure 4. Plot of a acquired at $45^{\circ} \mathrm{C}$ against total surface area for the three samples.

On the other hand, comparing the trend of $b$ values with particle size, pore volume, surface area and pore size shows no obvious relevance. As in most cases of linear fitting, the parameters corresponding to intercept cannot be estimated as accurate as those corresponding to slope $[31,33]$. Acquired $b$ values for the three samples are in the range of $(2.0 \pm 0.2) \times 10^{-5}$ mol. Such a difference cannot be safely used to identify the determinant effects of particle structure. This fraction of $\mathrm{SO}_{2}$ sink with constant capacity will be further discussed in the next section for temperature effects.

The measured breakthrough curves gives residence time distribution function $\mathrm{F}(\mathrm{t})$ that can be used to evaluate mass transfer effects in addition to adsorption capacity. In the case of linear and fast adsorption, i.e., eqn (5) applies, number of equivalent theoretical plate $(N E T P)$ can be estimated as follows. First convert $F(t)$ to density function $E(t)$ by

$$
E(t)=\frac{d F(t)}{d t}
$$

Since the nonlinear effects diminish during desorption period and for high concentrations, $\mathrm{E}(\mathrm{t})$ were calculated for the cases of $0.5 \%$ desorption. As shown in Figure 5, the obtained $\mathrm{E}(\mathrm{t})$ profiles exhibit typical Gaussian type distribution.

$$
N E P T=\alpha\left(\frac{\bar{t}}{W_{h / 2}}\right)^{2}
$$

where $\bar{t}$ is the average residence time corresponding to the peak position, $W_{h / 2}$ is width at half-height, $\alpha \approx 5.54$. The estimated NETP values are listed in Table 2. It may be seen NETP for the three samples are almost identical. NETP greater than 10 can be roughly correlated to effective diffusivity by

$$
N E T P=\frac{P e}{2}=\frac{1}{2} \frac{\tau_{D}}{\tau}=\frac{1}{2} \frac{L^{2} / D_{\text {eff }}}{V_{\operatorname{Re} a c t o r} \varepsilon / Q}
$$

Substituting $L=4.52 \mathrm{~cm}, V_{\text {Reactor }}=2 \mathrm{ml}$, pressure and temperature corrected flowrate $Q=77.1 \mathrm{ml} / \mathrm{min}$, NETP $=12$ and assuming column voidage $\varepsilon=0.4$ gives $D_{\text {eff }} \approx 1.3 \mathrm{~cm}^{2} / \mathrm{s}$.

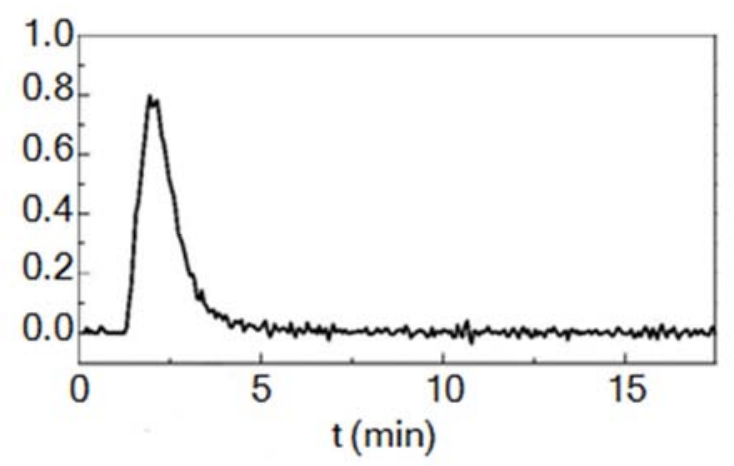

Figure 5. Typical E(t) profile converted from the breakthrough curve during desorption. 
Molecular diffusivity of $\mathrm{SO}_{2}$ in $\mathrm{N}_{2}$ estimated using the following equation is about $0.05 \mathrm{~cm}^{2} / \mathrm{s}$, much lower than Deff.

$$
D_{A B}=0.001085 \frac{\sqrt{T^{3}\left(\frac{1}{M_{A}}+\frac{1}{M_{B}}\right)}}{p \sigma_{A B}{ }^{2} \Omega_{D, A B}}
$$

Details of the equation and parameters can be found in reference [34]. In addition to negligible molecular diffusion along the axial direction, that NETP is independent of particle size suggests unimportant effects of eddy diffusion, which is approximately proportional to particle size. Actually, it may be estimated using Giddings' correlation that eddy diffusion accounts for less than $10 \%$ of the overall $\operatorname{HETP}(=\mathrm{L} / \mathrm{NETP})$ for the largest particle sample. The percentage is even lower for smaller samples. Moreover, particle size independent NETP indicates that pore diffusion across the open mesopores (referred to as particle voidage) in the particle is also fast and is not the limiting step. It may therefore be concluded that the overall band broadening effect is dominated by mass transfer between the gas in mesopores and the internal surface of the particle.

The above analysis on mass transfer kinetics provides valuable guidance for the practical design of supported IL materials and $\mathrm{SO}_{2}$ capture processes. First, since particle size does not have significant effects on NETP, larger particles may be used to reduce the pressure drop. Second, Zhang et al. ${ }^{[20]}$ found that there exist two kinds of pores with different sizes in porous $\mathrm{SiO}_{2}$ particles. Immobilized TMGL on $\mathrm{SiO}_{2}$ is mainly confined in the nanopores in the order of $10 \mathrm{~nm}$ while the pores in the order of $10^{4} \mathrm{~nm}$ remain unchanged even for $\mathrm{TMGL} / \mathrm{SiO}_{2}$ mass ratio up to $2 / 1$. According to our analysis, increasing the loading of TMGL on $\mathrm{SiO}_{2}$ may have significant effects on mass transfer kinetics, reducing the overall $\mathrm{SO}_{2}$ capture and adsorbent regeneration rates. Therefore, TMGL loading has contradicting effects on mass transfer and adsorption capacity. Process based simulation and optimization are required to search the compromise between these two factors.

\section{Effects of temperature}

Temperature affects several factors that directly determine the performance of $\mathrm{SO}_{2}$ capture. In this section, temperature effects on adsorption equilibrium and mass transfer coefficient are discussed.

Similar experiments as presented in the last section were carried out using sample I at several temperatures in the range of $25-65^{\circ} \mathrm{C}$. The acquired $a, b$, and NEPT values are summarized in Table 3. It is first seen that $a$ value consistently decreases with increased temperature. While $a$ consists of three terms as defined in eqn (9), the first two terms are negligible, i.e., $a$ is essentially proportional to $H_{V}$. As such, according to Van's Hoff correlation, plotting logarithm of $a$ against the inverse of temperature can be used to determine the enthalpy of this fraction of reversible physical adsorption. The plot and linear fits are shown in Figure 6. Physical adsorption enthalpy calculated from the slope is $-18.0 \mathrm{~kJ} / \mathrm{mol}$.
Table 3. $a, b$, NETP acquired at different temperatures for sample I.

\begin{tabular}{llll}
\hline $\mathbf{T}\left({ }^{\circ} \mathbf{C}\right)$ & $\mathbf{a}\left(\mathbf{1 0}^{-4} \mathbf{m}^{\mathbf{3}}\right)$ & $\mathbf{b}\left(\mathbf{1 0}^{\mathbf{- 5}} \mathbf{m o l}\right)$ & NETP \\
\hline 25 & 3.04 & 2.6 & 15 \\
35 & 2.39 & 2.7 & 14 \\
45 & 1.91 & 1.9 & 12 \\
55 & 1.49 & 2.3 & 10 \\
65 & 1.32 & 1.8 & 9 \\
\hline
\end{tabular}

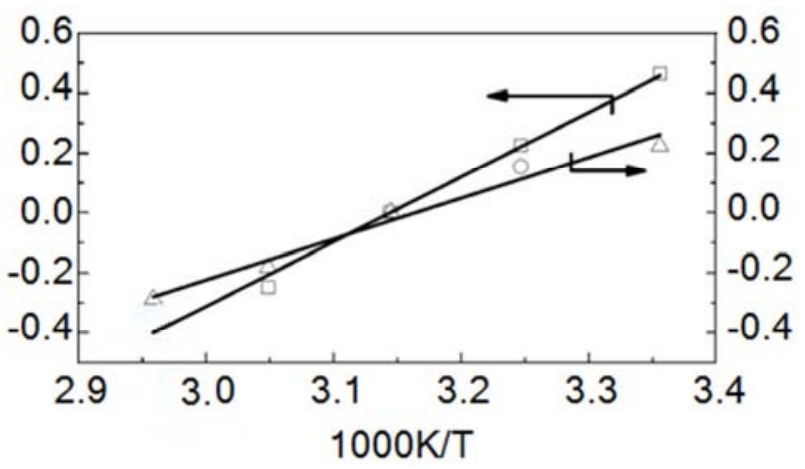

Figure 6. Temperature dependence of a and NETP for sample I.

Table 3 shows that NETP slightly decreases with increased temperature. This trend can be explained using eqn (6). It has been shown in the last section that the overall band broadening effect is dominated by mass transfer between the gas in mesopores and the internal surface of the particle. Therefore, $D_{L}$ can be neglected. In addition, since $a$ values are much greater than the reactor volume, $H_{V}$ is much greater than 1 . In this case, NETP is approximately proportional to the product of $H_{V}$ and $k_{m}$. Surface diffusion can be seen as an active process and is enhanced by increased temperature [35]. The activation energy can be estimated by plotting logarithm of NETP against the inverse of temperature as shown in Figure 6. The slope obtained by linear fitting corresponds to an energy of $11.3 \mathrm{~kJ} / \mathrm{mol}$, which is the difference between adsorption heat and activation energy of surface diffusion. The activation energy is therefore estimated to be $6.7 \mathrm{~kJ} / \mathrm{mol}$.

While temperature effects on both $a$ and NETP show clear trends that can be theoretically interpreted, the acquired $b$ values for different temperatures are randomly distributed in the range of $(2.2 \pm 0.4) \times 10^{-5} \mathrm{~mol}$. The deviation of $20 \%$ is acceptable for a number estimated from the intercept of linear fitting. It could therefore be determined that desorption from this fraction of $\mathrm{SO}_{2}$ sink is an activated process and cannot be efficiently activated up to $65^{\circ} \mathrm{C}$.

\section{Conclusions}

This work is focused on $\mathrm{SO}_{2}$ adsorption $\mathrm{SiO}_{2}$, which is the first step of our ongoing study towards the development of a comprehensive kinetic model for $\mathrm{SO}_{2}$ adsorption on $\mathrm{TMGL} / \mathrm{SiO}_{2}$, a supported ironic liquid material. A series of adsorption/desorption breakthrough experiments were performed using a micro-reactor system with precisely controlled flowrate, column temperature and pressure. Effects of concentration, particle structure and temperature on $\mathrm{SO}_{2}$ adsorption behaviors were systematically investigated. 
Theoretical analyses were carried out based on an isothermal and isobaric reactor model to identify the adsorption mechanisms and relative importance of various mass transfer effects.

It was found that $\mathrm{SO}_{2}$ adsorption on porous $\mathrm{SiO}_{2}$ can be divided into two fractions. The first fraction is physical adsorption that follows Henry's Law and can be reversibly regenerated by the purge of $\mathrm{N}_{2}$. Henry's constant of this fraction of adsorption is proportional to internal surface area. Temperature effect on Henry's constant can be well described by Van't Hoff equation and the physical adsorption enthalpy was estimated to be $-18.0 \mathrm{~kJ} / \mathrm{mol}$.

The second fraction can be seen as adsorption on the sites functioning as a sink with fixed $\mathrm{SO}_{2}$ capacity. $\mathrm{SO}_{2}$ adsorbed on these sites are stable and cannot be efficiently removed by the purge of $\mathrm{N}_{2}$ at temperatures up to $65^{\circ} \mathrm{C}$. This indicates that the desorption of this fraction of $\mathrm{SO}_{2}$ is an active process and needs to be activated at higher temperatures. The capacity of this fraction of capacity are not in direct correspondence with the particle size, internal surface area, pore volume and average pore size.

Due to the dual-site adsorption mechanism, the overall adsorption of $\mathrm{SO}_{2}$ on porous $\mathrm{SiO}_{2}$ is a nonlinear process. The nonlinear features are more important during the adsorption period and for low concentrations. The high concentration desorption breakthroughs that are dominated by linear physical adsorption were used to determine relative importance of various mass transfer processes. It was found that the NETP is not sensitive to particle size. Theoretical estimations showed that the contributions of molecular diffusion and eddy diffusion are also unimportant. The overall band broadening effect is mainly controlled by the mass transfer process between the gas in mesopores and the internal surface of the particle, which is an activated process and the activation energy was estimated to be $6.7 \mathrm{~kJ} / \mathrm{mol}$. This feature is of practical significance since the loading of ironic liquid on porous $\mathrm{SiO}_{2}$ may have contradicting effects on adsorption capacity and column efficiency. Process simulation and optimization are required to search the compromise between these two factors.

\section{Acknowledgements}

This work was supported by Zhejiang Provincial Natural Science Foundation (Y5110174) and National Natural Science Foundations of China (21376181).

\section{References}

[1] Lunt R. R and Cunic J. D. Profiles in Flue Gas Desulfurization. John Wiley \& Sons, Inc., Hoboken, NJ, USA, 2000.

[2] Srivastava R. K and Jozewicz W. Flue gas desulfurization: the state of the art. J Air Waste Manag Assoc. 2001; 51(12): 1676.

[3] Camper D, Scovazzo P, Koval C, Noble R. Gas Solubilities in Room-Temperature Ionic Liquids. Ind Eng Chem Res. 2004; 43: 3049 .
[4] AnthonyJ. L, Maginn E. J, Brennecke J. F. Solubilities and Thermodynamic properties of Gases in the Ionic Liquid 1-n-Butyl-3-Methylimidazolium Hexafluorophosphate. J Phys Chem B. 2002; 106:7315.

[5] Cadena C, Anthony J. L, Shah J. K, Morrow T. I, Brennecke J. F, Maginn E. J. Why Is $\mathrm{CO}_{2}$ so Soluble in Imidazolium-Based Ionic Liquids. J Am Chem Soc. 2004; 126: 5300.

[6] Bates E. D, Mayton R. D, Ntai I, Davis J. H. $\mathrm{CO}_{2}$ Capture by a Task-Specific Ionic Liquid. J Am Chem Soc. 2002; 124: 926.

[7] Zhang X, Zhang X. C, Dong H, Zhao Z, Zhang S, Huang Y. Carbon capture with ionic liquids: overview and progress. Energy Environ Sci. 2012; 5: 6668.

[8] Scovazzo P, Camper D, Kieft J, Poshusta J, Koval C, Noble R. Regular Solution Theory and $\mathrm{CO}_{2}$ Gas Solubility in Room-Temperature Ionic Liquids. Ind Eng Chem Res. 2004; 43: 6855 .

[9] Wu W. Z, Han B. X, Gao H. X, Liu Z. M, Jiang T, Huang J. Desulfurization of Fuel Gas: $\mathrm{SO}_{2}$ Absorption by an Ionic Liquid. Angew Chem Int Ed. 2004; 43: 2415.

[10] Huang J, Riisager A, Wasserscheid P, Fehrmann R. Reversible Physical Absorption of $\mathrm{SO}_{2}$ by Ionic Liquids. Chem Commun. 2006; 38: 4027.

[11] Huang J, Riisager A., Berg R. W, Fehrmann R. Tuning Ionic Liquids for High Gas Solubility and Reversible Gas Sorption. J Mol Cat A-Chem. 2008; 279: 170.

[12] Yuan X. L, Zhang S. J, Lu X. M. Hydroxyl Ammonium Ionic Liquids: Synthesis, Properties and Solubility of $\mathrm{SO}_{2}$. J Chem Eng Data. 2007; 52: 596.

[13] Anderson J. L, Dixon J. K, Maginn E. J, Brennecke J F. Measurement of $\mathrm{SO}_{2}$ solubility in Ionic Liquids. J Phys Chem B. 2006; 110: 15059 .

[14] Jiang Y. Y, Zhou Z, Jiao Z, Li L, Wu Y. T, Zhang Z. B. $\mathrm{SO}_{2}$ Gas Separation Using Supported Ionic Liquid Membranes. J Phys Chem B. 2007; 111: 5058.

[15] Yokozeki A, Shiflett M. B. Separation of carbon dioxide and sulfur dioxide gases using room-temperature ionic liquid [hmim]-[Tf2N]. Energy Fuels. 2009; 23:4701.

[16] Huang J, Riisager A, Wasserscheid P, Fehrmann R. Reversible physical absorption of $\mathrm{SO}_{2}$ by ionic liquids. Chem Commun.2006; 38: 4027.

[17] Anderson J. L, Dixon J. K, Maginn E. J, Brennecke J. F. Measurement of $\mathrm{SO}_{2}$ solubility in ionic liquids. J Phys Chem B. 2006; 110: 15059 .

[18] Wang C, Cui G, Luo X, Xu Y, Li H, Dai S. Highly efficient and reversible $\mathrm{SO}_{2}$ capture by tunable azole-based ionic liquids through multiple-site chemical absorption. J Am Chem Soc. 2011; 133:11916.

[19] Tang Y X, Mao W K, Ma N, et al. [Adsorption performances for sulfur dioxide using imidazole ionic liquids] [J]. Huan Jing Ke Xue, 2010, 31(31):2582-2586.

[20] $\mathrm{Qu} \mathrm{Y,} \mathrm{Lu.} \mathrm{Adsorption} \mathrm{of} \mathrm{five} \mathrm{adsorbents} \mathrm{for} \mathrm{different} \mathrm{ionic}$ liquids aqueous solutions $[\mathrm{J}]$. Chinese Journal of Environmental Engineering, 2012, 6(9):2969-2973. 
[21] Wishart J F. Energy applications of ionic liquids [J]. Energy \& Environmental Science, 2009, 2(9):956-961.

[22] Wang C, Ren S, Hou Y, et al. Absorption of $\mathrm{SO}_{2}$ in simulated flue gas with aqueous ionic liquid solutions [J]. Ciesc Journal, 2015, 66(S1):222-227.

[23] Huang K, Lu J F, Wu Y T, et al. Absorption of $\mathrm{SO}_{2}$, in aqueous solutions of mixed hydroxylammonium dicarboxylate ionic liquids [J]. Chemical Engineering Journal, 2013, s 215216(2):36-44.

[24] $\mathrm{Xu}$ J, Zha X, Wu Y, et al. Fast and highly efficient $\mathrm{SO}_{2}$ capture by TMG immobilized on hierarchical

micro-meso-macroporous AlPO-5/cordierite honeycomb ceramic materials $[\mathrm{J}]$. Chemical Communications, 2016, 52(38):6367-6370.

[25] Li X, Zhang L, Ying Z, et al. $\mathrm{SO}_{2}$ Absorption Performance Enhancement by Ionic Liquid Supported on Mesoporous Molecular Sieve [J]. Energy \& Fuels, 2015, 29(2):150105003334007.

[26] Chen K, Lin W, Yu X, et al. Designing of anion functionalized ionic liquids for efficient capture of $\mathrm{SO}_{2}$ from flue gas [J]. Aiche Journal, 2015, 61(6):2028-2034.

[27] Wu L. B, An D, Dong J, Zhang Z. M, Li B-G, Zhu S-P. Preparation and $\mathrm{SO}_{2}$ Absorption/Desorption Properties of Crosslinked Poly (1, 1, 3, 3-Tetramethylguanidinium Acrylate)
Porous Particles. Macromol Rapid Commun. 2006; 27: 1949.

[28] Zhang Z, Wu L, Dong J, Li B-G and Zhu S-P. Preparation and $\mathrm{SO}_{2}$ Sorption/Desorption Behavior of an Ionic Liquid Supported on Porous Silica Particles. Ind Eng Chem Res. 2009; 48: 2142.

[29] Li X, Zhang L, Zheng Y, Zheng Chuguang. $\mathrm{SO}_{2}$ Absorption Performance Enhancement by Ionic Liquid Supported on Mesoporous Molecular Sieve. Energy Fuels 2015; 29: 942.

[30] Jin M, Hou Y, Wu W, Ren S, Tian S, Xiao L, Lei Z. Solubilities and Thermodynamic Properties of $\mathrm{SO}_{2}$ in Ionic Liquids. J Phys Chem B. 2011; 115: 6585.

[31] H. S. Traub. Preparative Chromatography. Weinheim, Germany, 2005.

[32] Zha X. Master Thesis at Wenzhou University.

[33] Xu J, Zhu L, Xu G, Yu W, Ray A. K. Determination of competitive adsorption isotherm of enantiomers on preparative chromatographic columns using inverse method. J Chromatogr A. $2013 ; 1273: 49$.

[34] Bird R. B, Stewart W. E, Lightfoot E. N. Transport Phenomena. John Wiley \& Sons, New York, 1960.

[35] Gritti F, Guiochon G. Mass transfer kinetics, band broadening and column efficiency. J Chromatogr A. 2012; 1221: 2. 